\title{
Incidence of Scarlet Fever in Children in Jeju Province, Korea, 2002-2016: An Age-period-cohort Analysis
}

\author{
Jinhee Kim', Ji-Eun Kim', Jong-Myon Bae ${ }^{1,2}$ \\ ${ }^{\prime}$ Jeju Center for Infection Control, Jeju, Korea; ${ }^{2}$ Department of Preventive Medicine, Jeju National University School of Medicine, Jeju, Korea
}

Objectives: Outbreaks of scarlet fever in Mexico in 1999, Hong Kong and mainland China in 2011, and England in 2014-2016 have received global attention, and the number of notified cases in Korean children, including in Jeju Province, has also increased since 2010. To identify relevant hypotheses regarding this emerging outbreak, an age-period-cohort (APC) analysis of scarlet fever incidence was conducted among children in Jeju Province, Korea.

Methods: This study analyzed data from the nationwide insurance claims database administered by the Korean National Health Insurance Service. The inclusion criteria were children aged $\leq 14$ years residing in Jeju Province, Korea who received any form of healthcare for scarlet fever from 2002 to 2016. The age and year variables were categorized into 5 groups, respectively. After calculating the crude incidence rate (CIR) for age and calendar year groups, the intrinsic estimator (IE) method was applied to conduct the APC analysis.

Results: In total, 2345 cases were identified from 2002 to 2016. Scarlet fever was most common in the 0-2 age group, and boys presented more cases than girls. Since the CIR decreased with age between 2002 and 2016, the age and period effect decreased in all observed years. The IE coefficients suggesting a cohort effect shifted from negative to positive in 2009.

Conclusions: The results suggest that the recent outbreak of scarlet fever among children in Jeju Province might be explained through the cohort effect. As children born after 2009 showed a higher risk of scarlet fever, further descriptive epidemiological studies are needed.

Key words: Streptococcus pyogenes, Emm protein, Exotoxins, Scarlet fever, Cohort effect

\section{INTRODUCTION}

Scarlet fever is a pediatric infectious disease caused by group A streptococcus (GAS) bacteria that produce pyrogenic exotoxins, and affected patients commonly present with severe fever, sore throat, strawberry tongue, and skin rash [1]. Although the fatality rate of this disease has decreased to less than $1 \%$ after

Received: December 13, 2018 Accepted: April 2, 2019

Corresponding author: Jong-Myon Bae, MD, PhD

Department of Preventive Medicine, Jeju National University School of Medicine, 102 Jejudaehak-ro, Jeju 63243, Korea

E-mail: jmbae@jejunu.ac.kr

This is an Open Access article distributed under the terms of the Creative Commons Attribution Non-Commercial License (http://creativecommons.org/licenses/by$\mathrm{nc} / 4.0 /$ ) which permits unrestricted non-commercial use, distribution, and reproduction in any medium, provided the original work is properly cited. the advent of antibiotics [2], GAS infections kill over 500000 patients annually [3], and repeated infections can lead to autoimmune complications such as rheumatic disease and glomerulonephritis [1]. Thus, the Korean Centers for Disease Control and Prevention $(K C D C)$ designated this infection as a group 3 national notifiable infectious disease (NNID), and urges immediate notification of confirmed or suspected cases $[4,5]$.

Since the early 1980s, the number of reported GAS infections has been increasing globally $[6,7]$. Scarlet fever resurged in Mexico in 1999 [8], in Hong Kong and mainland China in 2011 [9-12], and in England in 2014-2016 [13,14]. Such paroxysmal occurrences of epidemics have been explained by the diversity of emm genotypes, which determine M-protein expression, a pathological determinant of GAS toxicity $[15,16]$. While emm 12 was the predominant genotype during the 2011 
outbreak in Hong Kong and China [11,17,18], emm3 was most prevalent in England in 2014 [14]. However, multiple factors (including GAS characteristics, climactic conditions, and herd immunity) contribute to the resurgence of GAS $[17,19,20]$, so that no definitive causal explanation has been established for recent outbreaks $[1,10,20]$.

The occurrence of scarlet fever in South Korea (hereafter Korea) has also spiked since $2011[5,7,21,22]$. The KCDC interpreted this increase as a phenomenon secondary to the expansion of scarlet fever notification criteria from confirmed patients to confirmed or suspected patients in September 2012 [23]. In addition, the KCDC simultaneously published a contradictory report stating that the number of insurance claims for scarlet fever received by the National Health Insurance Service (NHIS) actually decreased by $35.2 \%$ from 2011 to 2015 [24]. This suggests that a discrepancy exists between data on the reported cases of scarlet fever and data on filed insurance claims. Because Jeju Province reported an increase of over $50 \%$ in notifcations [25], there is a need to identify whether the heightened number of notifications is due to the increase in the total number of reports, resembling the national trend. In other words, it is necessary to determine the extent of the scarlet fever outbreak among children in Jeju Province based on the insurance claims filed with the NHIS and to suggest a hypothesis on this issue. Therefore, the aim of this study was to conduct a descriptive age-period-cohort (APC) epidemiological analysis of the scarlet fever outbreak in the pediatric population of Jeju Province based on NHIS insurance claim data.

\section{METHODS}

To conduct a descriptive analysis of scarlet fever patients in Jeju Province, the raw data were obtained from the customized health insurance database provided by the NHIS. This database represents an exhaustive survey created through the insurance claims filed with the NHIS by medical facilities when treatment is rendered to any Korean citizen $[5,26]$.

The inclusion criteria of this study were: (1) registered cases filed with the Korean Standard Classification of Diseases code A38 as the chief diagnosis code or any of the 9 co-diagnosis codes between 2002 and 2006, (2) patients with an administrative address in Jeju Province, and (3) patients aged 14 or younger at the time of filing. Multiple claims filed with the same code for a single patient within 1 year were assumed to reflect follow-up treatments after the diagnosis and were ex- cluded from the study.

The selected subjects were categorized into 5 age groups in 3-year units: 0-2 years, 3-5 years, 6-8 years, 9-11 years, and 1214 years. This categorization was developed to take into account the fact that scarlet fever is transmitted in the classroom environment $[2,20,22]$, meaning that appropriate school ages should be used in the classification [10]. The observations were also divided by calendar year into five 3-year chronological periods: 2002-2004, 2005-2007, 2008-2010, 2011-2013, and 2014-2016.

The crude incidence rate (CIR; per 1000 persons) of scarlet fever by sex, age, and chronological period was defined as a fraction in which the numerator was the number of scarlet fever patients, from the constructed database, within a given age group in a certain chronological period, and the denominator contained the sum of the mid-year population, from the information provided by the Statistics Korea, throughout that 3-year period.

The intrinsic estimator (IE) approach was applied for the APC analysis $[26,27]$ because it can resolve the issue of a linear dependency between age, period, and cohort, in which cohorts depend on age and period [28]. The apc_ie package, provided by Stata version 14 (StataCorp., College Station, TX, USA), was used to apply the IE approach. A normal distribution was used to calculate $95 \%$ confidence intervals ( $\mathrm{Cls}$ ) of prevalences, and the threshold for statistical significance was set at 0.05 . This study was deemed exempt from review by Jeju National University's Research Ethics Committee as it utilized secondary data that did not contain any personal information.

\section{RESULTS}

There was a total of 2345 cases of scarlet fever in Jeju Province between 2002 and 2016 in patients $0-14$ years of age. The most commonly affected age group was 0-2 years, with 1857 patients (79.2\%), and the incidence of scarlet fever decreased with age; there were 330 patients in the 3-5 age group (14.1\%), 117 patients in the 6-8 age group (5.0\%), 30 patients in the $9-11$ age group (1.3\%), and 11 patients in the 12-14 age group (0.5\%). The highest CIR was observed in the 0-2 age group between 2014 and 2016 (Table 1).

An analysis of the effects of age, period, and cohort on the $\mathrm{CIR}$ of scarlet fever during the study period showed that the CIR decreased as age increased when the effects of chronological period and cohort were corrected, and it also decreased 
Table 1. Crude incidence rates (CIR, per 1000 persons) by age group (0-14 years old) and calendar year (2002-2016) in children in Jeju Province, Korea

\begin{tabular}{|c|c|c|c|c|c|c|}
\hline \multirow{2}{*}{ Age (y) } & \multicolumn{5}{|c|}{ Year } & \multirow{2}{*}{ (Total, n } \\
\hline & 2002-2004 & 2005-2007 & 2008-2010 & 2011-2013 & 2014-2016 & \\
\hline $0-2$ & $3.21(204)$ & 3.61 (193) & 4.82 (247) & $11.42(584)$ & 12.08 (629) & (1857) \\
\hline $3-5$ & $3.36(252)$ & $0.61(40)$ & $0.24(13)$ & $0.30(16)$ & $0.16(9)$ & (33) \\
\hline 6-8 & 1.07 (86) & $0.27(20)$ & $0.08(5)$ & $0.09(5)$ & $0.02(1)$ & (117) \\
\hline $9-11$ & $0.29(23)$ & $0.04(3)$ & 0.04 (3) & $0.02(1)$ & $0(0)$ & (30) \\
\hline $12-14$ & $0.15(10)$ & $0.01(1)$ & $0(0)$ & $0(0)$ & $0(0)$ & (11) \\
\hline (Total, n) & (575) & (257) & (268) & (606) & (639) & 2345 \\
\hline
\end{tabular}

Table 2. Crude incidence rates (CIR, per 1000 persons) by age group (0-14 years old) and calendar year (2002-2016) in boys and girls in Jeju Province, Korea

\begin{tabular}{|c|c|c|c|c|c|c|c|c|c|c|}
\hline \multirow{2}{*}{ Age (y) } & \multicolumn{5}{|c|}{ Boys ( $n=1324)$} & \multicolumn{5}{|c|}{ Girls $(n=1021)$} \\
\hline & 2002-2004 & 2005-2007 & 2008-2010 & 2011-2013 & 2014-2016 & 2002-2004 & 2005-2007 & 2008-2010 & 2011-2013 & 2014-2016 \\
\hline $0-2$ & $3.74(125)$ & 3.61 (102) & 5.92 (157) & $12.97(341)$ & 12.70 (339) & $2.63(79)$ & $3.60(91)$ & $3.63(90)$ & 9.78 (243) & 11.43 (290) \\
\hline $3-5$ & 3.54 (139) & $0.61(21)$ & $0.31(9)$ & $0.36(10)$ & $0.14(4)$ & $3.16(113)$ & $0.61(19)$ & $0.15(4)$ & $0.23(6)$ & $0.18(5)$ \\
\hline $6-8$ & $0.95(40)$ & $0.20(8)$ & $0.09(3)$ & $0.10(3)$ & $0.03(1)$ & $1.20(46)$ & $0.33(12)$ & $0.06(2)$ & $0.08(2)$ & $0(0)$ \\
\hline $9-11$ & $0.29(12)$ & $0.07(3)$ & $0.03(1)$ & $0.03(1)$ & $0.00(0)$ & $0.30(11)$ & $0.00(0)$ & $0.06(2)$ & $0.00(0)$ & $0(0)$ \\
\hline $12-14$ & $0.12(4)$ & $0.02(1)$ & $0.00(0)$ & $0.00(0)$ & $0.00(0)$ & $0.19(6)$ & $0.00(0)$ & $0.00(0)$ & $0.00(0)$ & $0(0)$ \\
\hline
\end{tabular}

throughout the observational period when correcting for the age and cohort effects (Figure 1). However, a cohort effect appeared to be present, as shown by the finding that the CIR increased in children born after 2009 when the age and period effects were corrected.

The male-to-female ratio was 1.3:1 $(p<0.001)$, with 1324 boys (56.5\%; $95 \% \mathrm{Cl}, 54.6$ to 58.6 ) and 1021 girls (43.5\%; $95 \%$ $\mathrm{Cl}, 41.5$ to 45.5 ). By age group and chronological period, the highest CIR for boys was observed in the 0-2 age group in 2011-2013 and for girls in the 0-2 age group in 2014-2016 (Table 2). However, an analysis of the effects of age, period, and cohort on the CIR of scarlet fever during the observed period yielded equivalent results between the sexes (Figures 2 and 3 ). Thus, when the age and period effect were corrected, the cohort effect increased following its transition from negative to positive in 2009, but the age and period effects declined.

\section{DISCUSSION}

In summary, the incidence of scarlet fever in children in Jeju Province was higher in boys, while the incidence increased in both sexes for cohorts born after 2009 when the age and period effects were corrected. In other words, the elevated number of scarlet fever cases in children in Jeju Province was caused by a birth cohort effect, especially due to a higher CIR in children born after 2009.

Some interpret the recent increase in the incidence of scarlet fever in Korea as stemming from the KCDC's expansion of the notification criteria in September 2012 to include suspected cases as well as confirmed cases $[7,22,23]$. Such a change in the notification criteria may have induced an increase in the number of reports, but the following considerations weaken this explanation. First, according to the Health Insurance Review and Assessment Service, which is interconnected to the NHIS database, the reported incidence already reached 14550 patients by 2011 , before the abovementioned modification, which was made in September 2012 [5]. Second, the results of this study, derived from the NHIS database, suggest that the incidence was already spiking in the 2009-2011 birth cohort. Therefore, it may be concluded that an epidemic started in Korea around 2010, similar to the epidemic in Hong Kong and mainland China in 2011, and has been progressing ever since.

Furthermore, the improved availability of rapid detection kits and expanded insurance coverage could have influenced the increase in incidence. However, the effects of these factors may be less significant than previously estimated because, according to a press release from the KCDC [24], there has been a $35.2 \%$ reduction in overall medical treatment claims from 


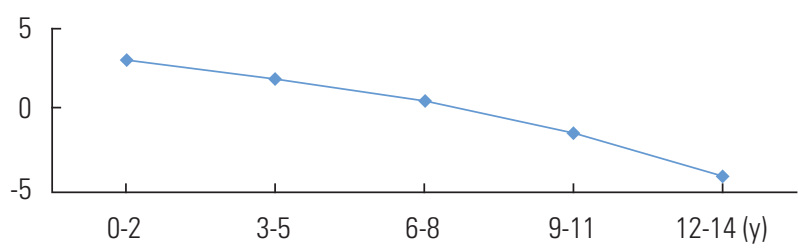

A
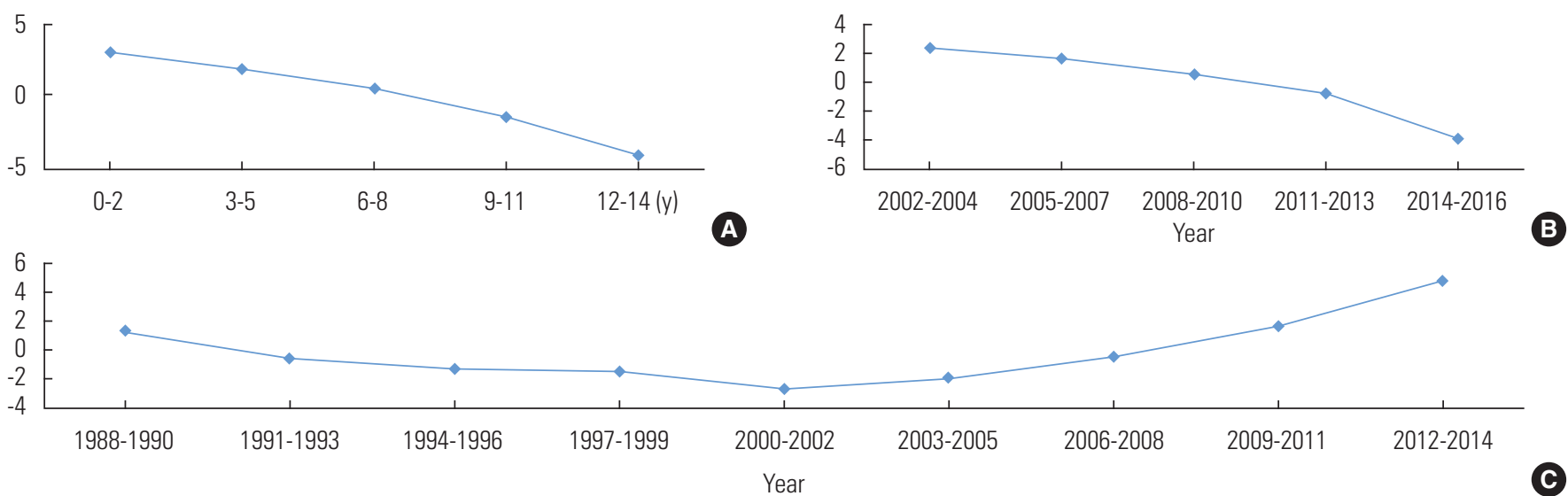

C

Figure 1. Intrinsic estimator analysis of age (A), period (B), and cohort (C) effects for scarlet fever based on crude incidence rates (per 1000 persons) by age (0-14 years old) and calendar year (2002-2016) in children in Jeju Province, Korea.
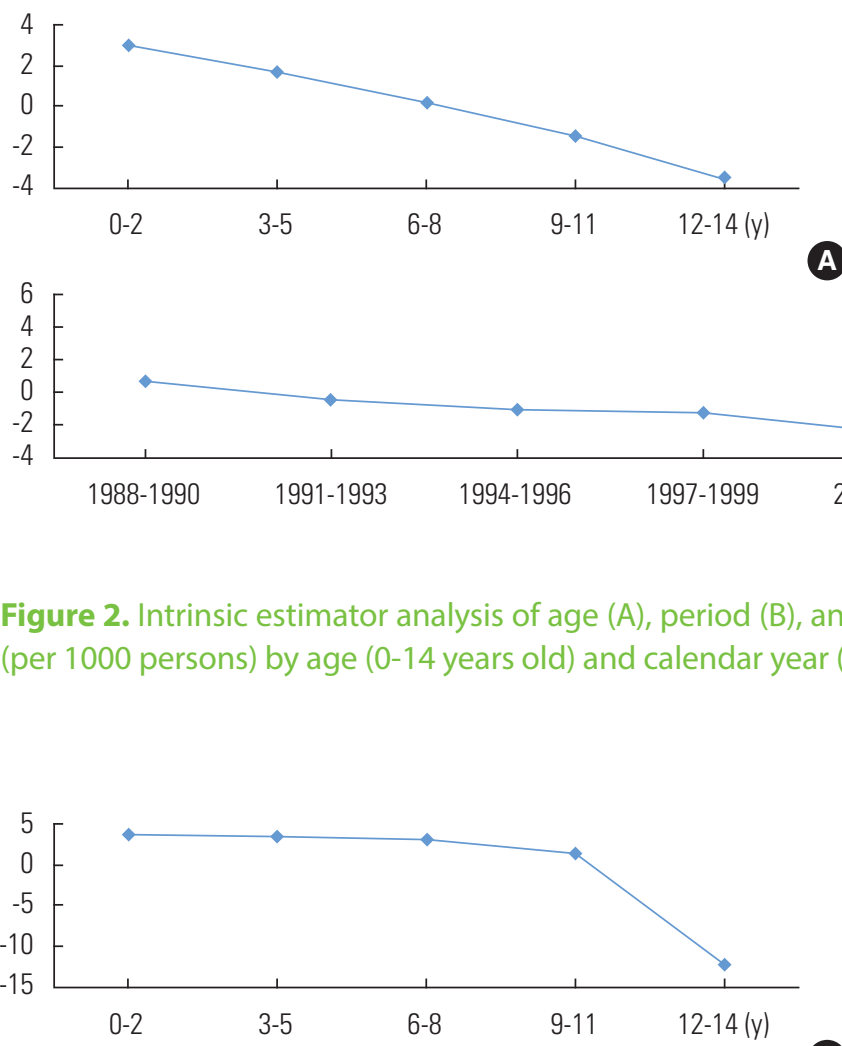

A

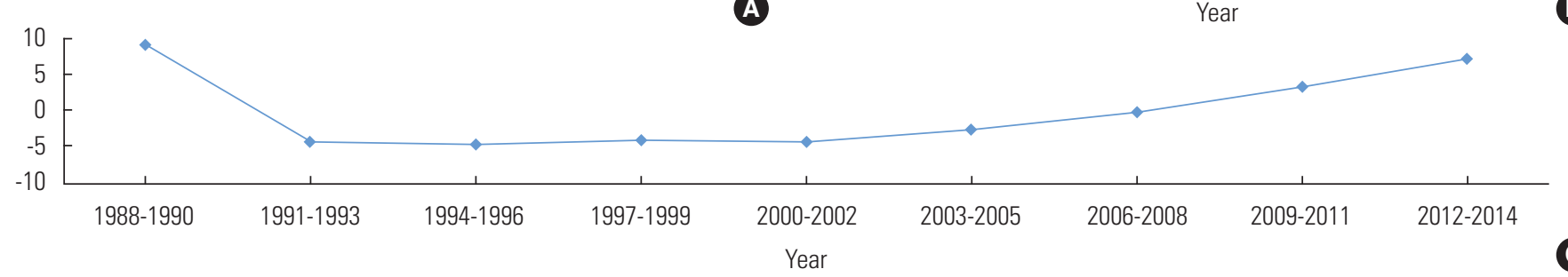

B

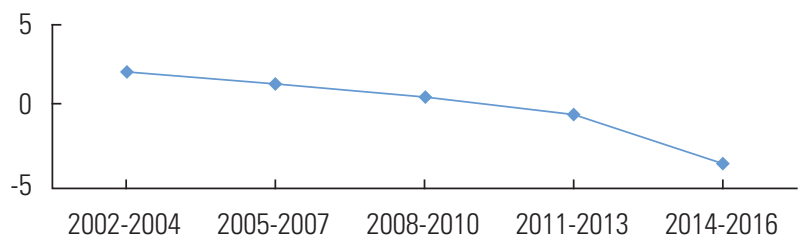

Year

C
Figure 2. Intrinsic estimator analysis of age (A), period (B), and cohort (C) effects for scarlet fever based on crude incidence rates (per 1000 persons) by age (0-14 years old) and calendar year (2002-2016) in boys in Jeju Province, Korea.

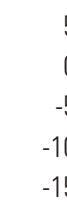

5


2011 to 2015, and the results of this study also suggest a consistent decrease in the period effect.

Interestingly, this study found the highest incidence of scarlet fever in the age group of $0-2$, whereas the most prevalent ages of scarlet fever patients in Hong Kong, Beijing, and England were $3-5,3-9$, and $3-7$, respectively $[10,14,29]$. This observation supports the theory that the risk of infection is influenced by the age at which children start school, which varies across cities and countries [22,29]. Recent changes in childrearing practices in Korea could be considered a cause for the highest incidence occurring in children between 0 year and 2 years of age. But it needs a further study for this hypothesis because scarlet fever is relatively rare in children under the age of 2 due to maternal antibodies [30].

Zhang et al. [31] reported a lower risk of scarlet fever in children between 3 years and 14 years of age when the average monthly temperature was above $20^{\circ} \mathrm{C}$, but they found no difference in risk in children under the age of 2 . Based on their findings, the climactic conditions of Jeju Province, the southernmost island of the Korean peninsula, may contribute to the incidence of scarlet fever. Further studies on the correlation between average monthly temperatures and the incidence of scarlet fever, along with a comparative study on the age of onset in areas of different latitudes, are needed.

The incidence was higher in boys, with a male-to-female ratio of 1.3:1. This observation resembles the findings from the outbreaks in Hong Kong [10], mainland China [12,29,32], and England [13]. Zhang et al. [29] explained this observation by pointing out the more active, but less hygienic practices, of boys. Unlike a study in Poland that found a steadily increasing male-to-female ratio from 1992 to 2001 [33], the male-to-female ratios in the 5 calendar-year groups in this study (1.25, $1.11,1.73,1.41$, and 1.17 ) showed no statistically significant trends (Table 2).

The main limitations of this study are as follows. First, the raw data were obtained through the NHIS database, which is constructed from filed insurance claims, and not the NNID database, which contains the actual reported cases of scarlet fever. However, the authors decided that the NHIS database was more suitable for the purpose of the study because APC analysis requires a database that is comprehensive and has longterm stability [24]. Furthermore, the NNID database has inherent limitations stemming from the relatively small number of reports [5,24,34] and delays in registration [35]. Second, the incidence of scarlet fever was based on rendered medical treatments following physicians' clinical and epidemiological diagnoses, indicating a susceptibility to possible overdiagnosis and misdiagnosis. However, the diagnosis of scarlet fever is based on clinical findings [36], and it can further be supported by the Centor score and clinical signs of febrile rash $[37,38]$. Further follow-up studies analyzing the clinical and epidemiological differences between confirmed cases and suspected cases are needed. Despite a report that $10 \%$ of scarlet fever cases are misdiagnosed as rubella [39], we believe that the effect of misdiagnosis on our results was minimal because the main subjects of the study were between the ages of 0 and 2 , an age group that receives mandatory vaccinations.

In conclusion, the increased incidence of scarlet fever in pediatric patients in Jeju Province was found to be due to the birth-cohort effect, and driven in particular by an increase in the cohorts born after 2009. Further descriptive epidemiological research, including a time-series analysis, is required to synthesize different hypotheses for the increased incidence in this birth cohort.

\section{SUPPLEMENTAL MATERIALS}

Korean version is available at https://www.jpmph.org/.

\section{CONFLICT OF INTEREST}

The authors have no conflicts of interest associated with the material presented in this paper.

\section{ORCID}

Jinhee Kim https://orcid.org/0000-0003-1629-9812

Ji-Eun Kim https://orcid.org/0000-0003-2845-3282

Jong-Myon Bae https://orcid.org/0000-0003-3080-7852

\section{REFERENCES}

1. Walker MJ, Barnett TC, McArthur JD, Cole JN, Gillen CM, Henningham $A$, et al. Disease manifestations and pathogenic mechanisms of group A Streptococcus. Clin Microbiol Rev 2014;27(2): 264-301.

2. Lee H. Outbreak investigation of scarlet fever in a kindergarten. Infect Chemother 2018;50(1):65-66.

3. Carapetis JR, Steer AC, Mulholland EK, Weber M. The global burden of group A streptococcal diseases. Lancet Infect Dis 
2005;5(11):685-694.

4. Park S, Cho E. National Infectious Diseases Surveillance data of South Korea. Epidemiol Health 2014;36:e2014030.

5. Kim JH, Cheong HK. Increasing number of scarlet fever cases, South Korea, 2011-2016. Emerg Infect Dis 2018;24(1):172-173.

6. Henningham A, Barnett TC, Maamary PG, Walker MJ. Pathogenesis of group A streptococcal infections. Discov Med 2012; 13(72):329-342.

7. Choi JH, Yang NR, Lee WJ, Lee H, Choi EH, Lee HJ. Distribution of emm types among group A Streptococcus isolates from children in Korea. Diagn Microbiol Infect Dis 2015;82(1):26-31.

8. Perea-Mejía LM, Inzunza-Montiel AE, Cravioto A. Molecular characterization of group A Streptococcus strains isolated during a scarlet fever outbreak. J Clin Microbiol 2002;40(1): 278-280.

9. Hsieh YC, Huang YC. Scarlet fever outbreak in Hong Kong, 2011. J Microbiol Immunol Infect 2011;44(6):409-411.

10. Lee CF, Cowling BJ, Lau EH. Epidemiology of reemerging scarlet fever, Hong Kong, 2005-2015. Emerg Infect Dis 2017;23(10): 1707-1710.

11. Chen M, Yao W, Wang X, Li Y, Chen M, Wang G, et al. Outbreak of scarlet fever associated with emm12 type group A Streptococcus in 2011 in Shanghai, China. Pediatr Infect Dis J 2012; 31(9):e158-e162.

12. Yang $P$, Peng $X$, Zhang D, Wu S, Liu Y, Cui S, et al. Characteristics of group A Streptococcus strains circulating during scarlet fever epidemic, Beijing, China, 2011. Emerg Infect Dis 2013;19(6): 909-915.

13. Guy R, Williams C, Irvine N, Reynolds A, Coelho J, Saliba V, et al. Increase in scarlet fever notifications in the United Kingdom, 2013/2014. Euro Surveill 2014;19(12):20749.

14. Lamagni T, Guy R, Chand M, Henderson KL, Chalker V, Lewis J, et al. Resurgence of scarlet fever in England, 2014-16: a population-based surveillance study. Lancet Infect Dis 2018;18(2): 180-187.

15. Tsoi SK, Smeesters PR, Frost HR, Licciardi P, Steer AC. Correlates of protection for $\mathrm{M}$ protein-based vaccines against group $\mathrm{A}$ Streptococcus. J Immunol Res 2015;2015:167089.

16. Yan JJ, Liu CC, Ko WC, Hsu SY, Wu HM, Lin YS, et al. Molecular analysis of group A streptococcal isolates associated with scarlet fever in southern Taiwan between 1993 and 2002. J Clin Microbiol 2003;41(10):4858-4861.

17. Tse H, Bao JY, Davies MR, Maamary P, Tsoi HW, Tong AH, et al. Molecular characterization of the 2011 Hong Kong scarlet fever outbreak. J Infect Dis 2012;206(3):341-351.
18. Davies MR, Holden MT, Coupland P, Chen JH, Venturini C, Barnett TC, et al. Emergence of scarlet fever Streptococcus pyogenes emm 12 clones in Hong Kong is associated with toxin acquisition and multidrug resistance. Nat Genet 2015;47(1): 84-87.

19. You Y, Davies MR, Protani M, McIntyre L, Walker MJ, Zhang J. Scarlet fever epidemic in China caused by Streptococcus pyogenes serotype M12: epidemiologic and molecular analysis. EBioMedicine 2018;28:128-135.

20. Wong SS, Yuen KY. Streptococcus pyogenes and re-emergence of scarlet fever as a public health problem. Emerg Microbes Infect 2012;1(7):e2.

21. Park DW, Kim SH, Park JW, Kim MJ, Cho SJ, Park HJ, et al. Incidence and characteristics of scarlet fever, South Korea, 20082015. Emerg Infect Dis 2017;23(4):658-661.

22. Ryu $S$, Chun BC. Investigation of scarlet fever outbreak in a kindergarten. Infect Chemother 2018;50(1):38-42.

23. Korea Centers for Diseases Control and Prevention. Guidelines for scarlet fever prevention and control 2017 [cited 2019 Feb 19]. Available from: http://www.cdc.go.kr/CDC/together/ CdcKrTogether0302.jsp? menulds =HOME006-MNU2804MNU3027-MNU2979\&cid = 138052 (Korean).

24. Korea Centers for Diseases Control and Prevention. Report of explanation of measles and scarlet fever; 2016 Dec 26 [cited 2019 Feb 19]. Available from: http://www.cdc.go.kr/CDC/notice/CdcKrIntro0201.jsp?menulds =HOME006-MNU2804MNU2937\&cid $=72443$ (Korean).

25. Kim MN, Han YJ, Yang DH, Bae JM. Status of national notifialbe infectious diseases in Jejudo, Korea: 2010-2017. J Med Life Sci 2017;12(2):51-56 (Korean).

26. Kim J, Kim JE, Bae JM. Incidence of varicella in children in Jejudo, Korea, 2005-2016: age-period-cohort analysis. Epidemiol Health 2018;40:e2018054.

27. Yang Y, Schulhofer-Wohl S, Fu WJ, Land KC. The intrinsic estimator for age-period-cohort analysis: what it is and how to use it. Am J Sociol 2008;113(6):1697-1736

28. Clayton $D$, Schifflers E. Models for temporal variation in cancer rates. II: age-period-cohort models. Stat Med 1987;6(4):469481.

29. Zhang Q, Liu W, Ma W, Shi Y, Wu Y, Li Y, et al. Spatiotemporal epidemiology of scarlet fever in Jiangsu Province, China, 20052015. BMC Infect Dis 2017;17(1):596.

30. Mahara G, Wang C, Huo D, Xu Q, Huang F, Tao L, et al. Spatiotemporal pattern analysis of scarlet fever incidence in Beijing, China, 2005-2014. Int J Environ Res Public Health 2016;13(1): 
E131.

31. Zhang Q, Liu W, Ma W, Zhang L, Shi Y, Wu Y, et al. Impact of meteorological factors on scarlet fever in Jiangsu province, China. Public Health 2018;161:59-66.

32. Liu Y, Chan TC, Yap LW, Luo Y, Xu W, Qin S, et al. Resurgence of scarlet fever in China: a 13-year population-based surveillance study. Lancet Infect Dis 2018;18(8):903-912.

33. Czarkowski MP, Kondej B, Staszewska E. Scarlet fever in Poland in 2011. Przegl Epidemiol 2013;67(2):203-206.

34. Chiou CS, Wang YW, Chen PL, Wang WL, Wu PF, Wei HL. Association of the shuffling of Streptococcus pyogenes clones and the fluctuation of scarlet fever cases between 2000 and 2006 in central Taiwan. BMC Microbiol 2009;9:115.

35. Yoo HS, Park O, Park HK, Lee EG, Jeong EK, Lee JK, et al. Timeli- ness of national notifiable diseases surveillance system in Korea: a cross-sectional study. BMC Public Health 2009;9:93.

36. Basetti S, Hodgson J, Rawson TM, Majeed A. Scarlet fever: a guide for general practitioners. London J Prim Care (Abingdon) 2017;9(5):77-79.

37. Choby BA. Diagnosis and treatment of streptococcal pharyngitis. Am Fam Physician 2009;79(5):383-390.

38. García-Vera C, de Dios Javierre B, Castán Larraz B, Arana Navarro T, Cenarro Guerrero T, Ruiz Pastora $R$, et al. Scarlet fever: a not so typical exanthematous pharyngotonsillitis (based on 171 cases). Enferm Infecc Microbiol Clin 2016;34(7):422-426.

39. Czarkowski MP, Staszewska E, Kondej B. Scarlet fever in Poland in 2013. Przegl Epidemiol 2015;69(2):223-227. 